\title{
Suicidal Behaviors Among Public Community Healthcare Center Registrants: A Comparison of Mental and General Healthcare Center Registrants in Korea
}

\author{
Kyuhong Lee, MD¹, Hoo Rim Song, MD, PhD¹, Su Young Lee, MD, PhD', Tae-Youn Jun, MD, PhD², \\ Hae Kook Lee, MD, $\mathrm{PhD}^{3}$, Jong-Hyun Jeong, $\mathrm{MD}, \mathrm{PhD}^{4}$, Sun-Jin Jo, $\mathrm{PhD}^{5}$ \\ ${ }^{1}$ Department of Psychiatry, Myongii Hospital, Hanyang University Medical Center, Goyang, ${ }^{2}$ Department of Psychiatry, Yeouido St. Mary's Hos- \\ pital, The Catholic University of Korea, Seoul, ${ }^{3}$ Department of Psychiatry, Uijeongbu St. Mary's Hospital, The Catholic University of Korea, \\ Uijeongbu, ${ }^{4}$ Department of Psychiatry, St. Vincent's Hospital, The Catholic University of Korea, Suwon, ${ }^{5}$ Department of Preventive Medi- \\ cine, College of Medicine, The Catholic University of Korea, Seoul, Korea
}

Background: The study examined the prevalence of suicidal ideation and suicide attempts among registrants of public community healthcare centers and compared between the characteristics of mental and general healthcare center (GHC) registrants.

Methods: The study measured lifetime suicidal behaviors, psychosocial variables, psychiatric comorbidities, and suicide related factors.

Results: A total of $132(73.7 \%)$ and 126 (42.3\%) mental and GHC registrants, respectively, reported a history of suicidal ideation; whereas $64(35.8 \%)$ and $29(9.7 \%)$ of mental and GHC registrants, respectively, reported a history of suicidal attempts. Scores of the Beck Depression Inventory (BDI) for both suicidal ideation groups were above the severe level, although only $2 \%$ of GHC group recognized their diagnoses of depressive disorders.

Conclusion: The study observed high suicidal risk among the mental and GHC registrants. High BDI scores and unevaluated depression under score the need for screening and provision of appropriate early interventions in public community healthcare centers.

Keywords Suicide; Depression; Public community healthcare center

\section{INTRODUCTION}

Suicide is one of the most common causes of death worldwide. In particular, among the members of the Organization for Economic Cooperation and Development, Korea has the highest suicide rate, and there has been a two-fold increase in this figure over the past two decades [1].

In many countries, suicide rates have been lowered by enhancing the social and mental health systems that serve individuals who are at high risk for suicide [2]. In Korea, public community healthcare centers, including general healthcare centers (GHCs) and mental healthcare centers (MHCs), have been opened nationwide to fulfill a significant role in social health system by government. GHCs have been established at the municipal, county, and district levels to promote and improve general health. It performs basic medical work, dedicated to preventive health administrations such as management of metabolic syndrome and smoking cessation. MHCs, which are complementary to GHCs, conduct programs that facilitate the early detection of individuals who are at high risk for mental health problems. They also provide rehabilitation and promote the management of

Received October 1, 2020, Revised October 22, 2020, Accepted October 22, 2020

Correspondence: Hoo Rim Song, MD, PhD

Department of Psychiatry, Myongji Hospital, Hanyang University Medical Center, 55 Hwasu-ro 14beon-gil, Deogyang-gu, Goyang 10475, Korea

TEL +82-31-810-5114 FAX +82-31-969-0500 E-mail drsong@empas.com ORCID https://orcid.org/0000-0001-8927-0530

Copyright $@$ by Korean Society for Affective Disorders. All Rights reserved.

This is an Open Access article distributed under the terms of the Creative Commons Attribution Non-Commercial License (http://creativecommons.org/licenses/ by-nc/4.0/) which permits unrestricted non-commercial use, distribution, and reproduction in any medium, provided the original work is properly cited. 
chronic mental illness among the members of their local communities. GHC registrants are primarily members of the general population. In contrast, MHC registrants are primarily psychiatric patients. Although these public centers should have gatekeeping function of suicidal behaviors, even the basic status of suicide in there has not been researched enough.

Therefore, this study aimed to ascertain the prevalence of suicidal ideation and attempts among public community healthcare center registrants in Korea. A further aim was to investigate the characteristics and comorbidities related with suicidal behaviors with comparison of MHC and GHC. If this research suggests that the suicidal behavior of GHC registrants should be concerned as the suicidal behavior of MHC registrants, GHC should have an additional gatekeeper role for suicidal behavior to reduce the suicide rate in Korea.

\section{MATERIALS AND METHODS}

Participants were public community healthcare center registrants in three urban areas as Suwon, Pocheon, and Youngdeungpo (Seoul). Inclusion criteria were MHC and GHC registrants who consent to fulfillment of case report form. In order to enhance the representativeness of the sample, the survey was simultaneously conducted at the three GHCs and three MHCs for nine hours on a sample day. A total of 477 participants agreed to participate in the study. We followed all the applicable institutional and governmental regulations concerning the ethical treatment of human volunteers, and this study was approved by the Institutional Review Board of Myongji Hospital (IRB No. 2019-08-011).

The survey measured the lifetime prevalence of suicide behaviors and scales for suicide-related factors along with basic demographic data. Similar to the measurement strategy used in the Korean National Survey of Mental Disorders [3], lifetime suicidal ideation and attempts were assessed using the following two direct questions: (1) "Have you ever thought about committing suicide?" and (2) "Have you ever actually attempted suicide?"

Several scales were used to assess the content and risk factors of suicidal behavior. Suicide-related factors, namely, depression, impulsiveness, aggressiveness, alcohol use, hopelessness, suicidal severity, reasons for living, childhood trauma, social support, and family relationships were assessed using the Beck Depressive Inventory [4], Barratt Impulsiveness Scale [5], BussPerry Aggression Questionnaire [6], Alcohol Use Disorders Identification Test-Concise (AUDIT-C) [7], Beck Suicide Ideation Scale [4], Beck Hopelessness Scale [4], Linehan's Reasons for Living Inventory [4], Modified Childhood Trauma Questionnaire [8], Social Support Scale [9], and Family Relationship Scale [10], respectively.

Descriptive statistics were computed to examine the distribution of each variable within the two groups. Chisquared test was used to examine differences in the categorical variables between the MHC and GHC registrants as well as to test the independence between each factor and suicidal ideation within each group. Student's t-test was conducted to examine group differences in age, educational level, and total scale scores. The significance level was defined as $p<0.05$. All statistical analyses were conducted using PASW Statistics for Windows, Version 18.0 (SPSS Inc., Chicago, IL, USA).

\section{RESULTS}

\section{Total sample}

Table 1 presents the participants' demographic characteristics, the prevalence of suicidal behaviors, the characteristics that were related to suicidal risk, and the results of comparisons of the $\mathrm{MHC}$ and $\mathrm{GHC}$ registrants.

\section{Demographic characteristics}

There was no significant difference in age, sex, and educational level (years). A higher percentage of the MHC registrants were unemployed $(\mathrm{n}=119,66.5 \%$ vs. $\mathrm{n}=89,29.9 \%, \mathrm{p}<0.001)$ and living alone $(\mathrm{n}=45,25.1 \%$ vs. $\mathrm{n}=30,10.3 \%, \mathrm{p}<0.001)$. More believers and their religions were reported by MHC registrants than by GHC registrants $(128[71.5 \%]$ vs. $171[57.1 \%])$ and their main religions were Protestantism and no religion (77 [43.0\%] and 127 [42.9\%]), respectively. Among the MHC registrants, the most commonly self-reported psychiatric diagnoses were schizophrenia spectrum disorders $(\mathrm{n}=96$, $53.6 \%)$, followed by depressive $(\mathrm{n}=37,20.7 \%)$ and bipolar $(\mathrm{n}=16,8.9 \%)$ spectrum disorders. In contrast, only $8(2.6 \%)$ GHC registrants recognized their psychiatric diagnoses. Further, substantially fewer GHC registrants 
Table 1. Characteristics of subjects in the MHC registrants and in the GHC registrants

\begin{tabular}{|c|c|c|c|}
\hline Variable & MHC registrant & GHC registrant & p-value \\
\hline Total number & 179 & 298 & \\
\hline Sex (male/female) & $81 / 98(55.1)$ & $128 / 170(57.0)$ & 0.672 \\
\hline Age $(y)$ & $46.12 \pm 12.96$ & $46.36 \pm 17.30$ & 0.325 \\
\hline Total educated years (y) & $11.49 \pm 4.31$ & $11.83 \pm 3.49$ & 0.667 \\
\hline Religion & & & $0.002 \star \star x$ \\
\hline Buddhism & $22(12.3)$ & $50(16.8)$ & \\
\hline Catholic & $24(13.4)$ & $30(10.1)$ & \\
\hline Protestantism & $77(43.0)$ & $84(28.4)$ & \\
\hline No religion & $51(28.5)$ & $127(42.9)$ & \\
\hline Others & $5(2.8)$ & $5(1.7)$ & \\
\hline Unemployed & $119(66.5)$ & $89(29.9)$ & $<0.001 * \star \star *$ \\
\hline Living alone & $45(25.1)$ & $30(10.3)$ & $<0.001 \star \star \star$ \\
\hline Self-recognized diagnosis & & & $<0.001 * * *$ \\
\hline Depressive disorders & $37(20.7)$ & $6(2.0)$ & \\
\hline Bipolar spectrum disorders & $16(8.9)$ & $0(0.0)$ & \\
\hline Schizophrenia spectrum disorders & $96(53.6)$ & $2(0.6)$ & \\
\hline Medical illness & $30(16.8)$ & $84(28.2)$ & \\
\hline Under treatment for diagnosis & $134(74.9)$ & $62(20.8)$ & $<0.001 * \star \star$ \\
\hline Smoker & $69(38.5)$ & $55(18.5)$ & $<0.001 * \star \star *$ \\
\hline Suicidal ideation & $132(73.7)$ & $126(42.3)$ & 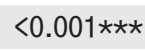 \\
\hline Suicidal attempt & $64(35.8)$ & $29(9.7)$ & $<0.001 * \star *$ \\
\hline Familial suicide history & $31(17.3)$ & $31(10.4)$ & 0.067 \\
\hline Beck Depression Inventory & $45.00 \pm 13.11$ & $37.68 \pm 10.62$ & $0.003 * \star$ \\
\hline Barratt Impulsiveness Scale & $27.34 \pm 8.68$ & $28.49 \pm 8.33$ & 0.496 \\
\hline Buss-Perry Aggression Questionnaire & $77.10 \pm 35.18$ & $67.43 \pm 29.90$ & $0.002 \star \star$ \\
\hline AUDIT-C & $2.15 \pm 3.11$ & $3.71 \pm 3.69$ & $<0.001 * \star \star$ \\
\hline Beck Hopelessness Scale & $8.62 \pm 5.42$ & $6.11 \pm 4.85$ & 0.070 \\
\hline Scale for Suicidal Ideation & $12.89 \pm 10.09$ & $6.33 \pm 7.70$ & $<0.001 * \star \star$ \\
\hline Brief Reason for Living Inventory & $46.76 \pm 15.43$ & $53.13 \pm 15.47$ & 0.507 \\
\hline Modified Childhood Trauma Questionnaire & $23.16 \pm 11.54$ & $20.86 \pm 9.21$ & $<0.001 * \star \star *$ \\
\hline Social Support Scale & $29.36 \pm 7.16$ & $30.10 \pm 7.25$ & 0.516 \\
\hline Family Relationship Scale & $66.60 \pm 15.51$ & $73.39 \pm 14.03$ & 0.184 \\
\hline
\end{tabular}

Values are presented as number only, number (\%), or mean \pm standard deviation.

MHC, mental healthcare center; GHC, general healthcare center; AUDIT-C, Alcohol Use Disorders Identification Test-Concise.

$\star p<0.05, * \star p<0.01, * * * p<0.001$.

were receiving treatment for their illnesses $(n=134$, $74.9 \%$ vs. $n=62,20.8 \%, p<0.001)$. Smokers were more in the $\operatorname{MHC}(\mathrm{n}=69,38.5 \%$ vs. $\mathrm{n}=55,18.5 \%, \mathrm{p}<0.001)$.

\section{Lifetime prevalence of suicidal ideation and attempts}

The lifetime prevalence of suicidal ideation was 132 (73.7\%) among the MHC registrants and 126 (42.3\%) among the GHC registrants $(\mathrm{p}<0.001)$. Further, 64 (35.8\%) MHC registrants and 29 (9.7\%) GHC registrants $(\mathrm{p}<0.001)$ had attempted suicide. There was no significant group difference in familial suicide history $(n=31$, $17.3 \%$ vs. $n=31,10.4 \%, p=0.067$ ).

\section{Characteristics related to suicidal risk}

There were statistically significant differences in scores on the BDI $(45.00 \pm 13.11$ vs. $37.68 \pm 10.62$, $\mathrm{p}=0.003)$, Buss-Perry Aggression Questionnaire $(77.10 \pm 35.18$ vs. $67.43 \pm 29.90, p=0.002)$, AUDIT-C $(2.15 \pm 3.11$ vs. $3.71 \pm 3.69, \mathrm{p}<0.001)$, Scale for Suicidal 
Ideation $(12.89 \pm 10.09$ vs. $6.33 \pm 7.70, \mathrm{p}<0.001)$, and Modified Childhood Trauma Questionnaire (23.16 \pm 11.54 vs. 20.86 $\pm 9.21, \mathrm{p}<0.001)$. The $\mathrm{MHC}$ registrants scored significantly higher, while AUDIT-C revealed GHC registrants have more severe alcohol problem close to the cutoff score (4 for male 3 for female for screening test).
There were no significant group differences in scores on the Barratt Impulsiveness Scale, Beck Hopelessness Scale, Brief Reasons for Living Inventory, Social Support Scale, and Family Relationship Scale. The scores of BDI of both groups were above severe level (score above 23) in common.

Table 2. Characteristics of subject having suicidal ideation history in the MHC registrants and in the GHC registrants

\begin{tabular}{|c|c|c|c|}
\hline Variable & $\mathrm{MHC}$ registrant & $\mathrm{GHC}$ registrant & p-value \\
\hline Total number & 132 & 126 & \\
\hline Sex (male/female) & $78 / 132(59.1)$ & $74 / 126(58.7)$ & 0.895 \\
\hline Age (y) & $45.21 \pm 13.49$ & $45.43 \pm 17.01$ & 0.293 \\
\hline Total educated years (y) & $11.49 \pm 4.74$ & $11.22 \pm 3.65$ & 0.454 \\
\hline Religion & & & $0.032 \star$ \\
\hline Buddhism & $18(13.6)$ & $13(10.3)$ & \\
\hline Catholic & $16(12.1)$ & $13(10.3)$ & \\
\hline Protestantism & $53(40.2)$ & $42(33.3)$ & \\
\hline No religion & $40(30.3)$ & $58(46.0)$ & \\
\hline Other religion & $5(3.8)$ & $0(0.0)$ & \\
\hline Unemployed & $87(65.9)$ & $37(29.4)$ & $<0.001 \star \star \star *$ \\
\hline Living alone & $44(33.3)$ & $17(13.5)$ & $<0.001 \star \star \star *$ \\
\hline Self-recognized diagnosis & & & $<0.001 \star \star \star *$ \\
\hline Depressive disorders & $34(25.8)$ & $5(3.9)$ & \\
\hline Bipolar spectrum disorders & $12(9.2)$ & $0(0.0)$ & \\
\hline Schizophrenia spectrum disorders & $62(47.0)$ & $0(0.0)$ & \\
\hline Medical illness & $24(18.2)$ & $36(28.5)$ & \\
\hline Under treatment for diagnosis & $99(75.0)$ & $26(20.6)$ & $0.044 \star$ \\
\hline Smoker & $48(36.3)$ & $34(26.9)$ & 0.127 \\
\hline Reason for suicidal ideation & & & $0.004 \star \star$ \\
\hline School achievement & $1(0.8)$ & $9(7.1)$ & \\
\hline Future career & $30(22.9)$ & $7(5.6)$ & \\
\hline Social problem & $24(18.3)$ & $15(11.9)$ & \\
\hline Financial burden & $30(22.9)$ & $20(15.9)$ & \\
\hline Interpersonal problem & $22(16.6)$ & $32(25.3)$ & \\
\hline Others & $9(6.9)$ & $3(2.4)$ & \\
\hline Suicidal attempt & $64(48.4)$ & $29(23.0)$ & $<0.001 \star * *$ \\
\hline Familial suicide history & $27(20.4)$ & $18(14.2)$ & $<0.001 * \star *$ \\
\hline Beck Depression Inventory & $47.19 \pm 12.66$ & $41.30 \pm 11.06$ & 0.236 \\
\hline Barratt Impulsiveness Scale & $27.81 \pm 8.44$ & $29.11 \pm 8.04$ & 0.575 \\
\hline Buss-Perry Aggression Questionnaire & $80.45 \pm 36.75$ & $74.59 \pm 31.72$ & 0.052 \\
\hline AUDIT-C & $2.31 \pm 3.27$ & $3.65 \pm 3.77$ & $0.019 *$ \\
\hline Beck Hopelessness Scale & $9.36 \pm 5.44$ & $7.36 \pm 5.38$ & 0.601 \\
\hline Scale for Suicidal Ideation & $15.37 \pm 9.73$ & $10.30 \pm 8.59$ & $0.040 *$ \\
\hline Brief Reason for Living Inventory & $45.88 \pm 15.62$ & $51.96 \pm 12.55$ & $0.019 *$ \\
\hline Modified Childhood Trauma Questionnaire & $23.51 \pm 11.57$ & $23.00 \pm 10.51$ & 0.373 \\
\hline Social Support Scale & $29.52 \pm 7.33$ & $30.60 \pm 7.30$ & 0.457 \\
\hline Family Relationship Scale & $64.89 \pm 16.21$ & $70.57 \pm 12.89$ & $0.017 *$ \\
\hline
\end{tabular}

Values are presented as number only, number (\%), or mean \pm standard deviation.

MHC, mental healthcare center; GHC, general healthcare center; AUDIT-C, Alcohol Use Disorders Identification Test-Concise.

$\star p<0.05, * \star p<0.01, * \star \star p<0.001$. 


\section{Participants with a history of suicidal ideation}

Among total population of 179 in $\mathrm{MHC}$ and 298 in GHC registrants, 132 (73.7\%) and 126 (42.3\%) registrant reported they had suicidal ideations during whole life. Table 2 presents their demographic characteristics and the factors that were related to suicidal risk among MHC and GHC registrants with a history of suicidal ideation.

\section{Demographic characteristics}

There were no significant group differences in age, sex, educational level (years), and smoking status. A higher percentage of the MHC registrants were unemployed $(\mathrm{n}=87,65.9 \%$ vs. $\mathrm{n}=37,29.4 \%, \mathrm{p}<0.001)$ and living alone $(\mathrm{n}=44,33.3 \%$ vs. $\mathrm{n}=17,13.5 \%, \mathrm{p}<0.001)$. The main religion of $\mathrm{MHC}$ registrants was Protestantism $(\mathrm{n}=53,40.2 \%)$, while it of GHC was no religion $(\mathrm{n}=58$, $46.0 \%$ ). Among the MHC registrants, the most commonly reported psychiatric diagnoses were schizophrenia spectrum disorders $(\mathrm{n}=62,47.0 \%)$, followed by depressive $(n=34,25.8 \%)$ and bipolar $(n=12,9.2 \%)$ spectrum disorders. In contrast, only 5 (3.9\%) GHC registrants recognized their psychiatric diagnoses (i.e., depressive disorders). The MHC registrants had less medical illness than the GHC registrants ( $\mathrm{n}=24,18.2 \%$ vs. $\mathrm{n}=36,28.5 \%$ ). Further, a substantially higher percentage of the MHC registrants were receiving treatment for their illnesses ( $n=99,75.0 \%$ vs. $n=26,20.6 \%, p=0.044)$.

With regard to the reasons underlying suicidal ideation, financial burden and future career were the two most commonly reported reasons (both: $n=30,22.9 \%$ ) among the $\mathrm{MHC}$ registrants, and interpersonal problems were the most commonly reported reason $(n=32,25.3 \%)$ among the GHC registrants. The percentage of individuals who were suicide attempters was significantly higher among the $\mathrm{MHC}$ registrants than among the $\mathrm{GHC}$ registrants ( $\mathrm{n}=64,48.4 \%$ vs. $\mathrm{n}=29,23.0 \%, \mathrm{p}<0.001$ ).

\section{Characteristics related to suicidal risk}

Familial suicide history was more commonly observed among the MHC registrants ( $\mathrm{n}=27,20.4 \%)$ than among the GHC registrants $(\mathrm{n}=18,14.2 \%, \mathrm{p}<0.001)$. Further, there were statistically significant group differences in scores on the AUDIT-C (2.31 \pm 3.27 vs. $3.65 \pm 3.77$, $\mathrm{p}=0.019)$, Scale for Suicidal Ideation $(15.37 \pm 9.73$ vs. $10.30 \pm 8.59, \mathrm{p}=0.04)$, Brief Reasons for Living Inventory
$(45.88 \pm 15.62$ vs. $51.96 \pm 12.55, \mathrm{p}=0.019)$, and Family Relationship Scale $(64.89 \pm 16.21$ vs. $70.57 \pm 12.89, \mathrm{p}=0.017)$.

The MHC registrants obtained significantly higher scores on the Scale for Suicidal Ideation and lower scores on the Brief Reasons for Living Inventory. However, the GHC registrants obtained higher scores on the AUDIT-C. On the other hand, the scores of BDI in who had suicidal ideation were not different in both groups (47.19 \pm 12.66 vs. $41.3 \pm 11.06, p=0.236)$. also which was above severe level, and not different from them of total population in the clinical meaning. Further, there were no significant group differences in scores on the Barratt Impulsiveness Scale, Buss-Perry Aggression Questionnaire, Beck Hopelessness Scale, Modified Childhood Trauma Questionnaire, Social Support Scale, and Family Relationship Scale.

\section{Participants with a history of suicidal attempts}

Of the $132 \mathrm{MHC}$ registrants and $126 \mathrm{GHC}$ registrants who reported a history of suicidal ideation, 64 (48.4\%) and $29(23.0 \%)$ individuals also reported a history of suicidal attempts, respectively. Table 3 presents their demographic characteristics and the factors that were related to suicidal risk among the MHC and GHC registrants with a history of suicidal attempts.

\section{Demographic characteristics}

There were no significant group differences in age, sex, educational level (years), religion, and employment and smoking status. A higher percentage of the MHC registrants were living alone ( $\mathrm{n}=19,29.7 \%$ vs. $\mathrm{n}=2,7.4 \%$, $\mathrm{p}=0.002$ ). Among the MHC registrants, the most commonly self-reported psychiatric diagnoses were schizophrenia spectrum disorders $(\mathrm{n}=29,45.3 \%)$, followed by depressive $(n=18,28.1 \%)$ and bipolar $(n=8,12.5 \%)$ spectrum disorders. Only 4 (13.7\%) GHC registrants recognized their psychiatric diagnoses (i.e., depressive disorders). Further, a substantially higher percentage of the MHC registrants were receiving treatment for their illnesses ( $\mathrm{n}=46,71.9 \%$ vs. $\mathrm{n}=4,13.7 \%, \mathrm{p}=0.001)$.

With regard to the reasons underlying suicidal ideation, financial burden was the most commonly reported reason $(\mathrm{n}=27,42.2 \%)$ among the $\mathrm{MHC}$ registrants, and interpersonal problems $(n=11,37.9 \%)$ were the most commonly reported reason among the GHC registrants. 
Table 3. Characteristics of subject having suicide attempt history in the MHC registrants and in the GHC registrants

\begin{tabular}{|c|c|c|c|}
\hline Variable & $\mathrm{MHC}$ registrant & $\mathrm{GHC}$ registrant & p-value \\
\hline Total number & 64 & 29 & \\
\hline Sex (male/female) & $38 / 64(59.4)$ & $12 / 29(41.4)$ & 0.107 \\
\hline Age (y) & $44.01 \pm 12.26$ & $40.85 \pm 12.73$ & 0.928 \\
\hline Total educated years (y) & $11.56 \pm 5.17$ & $11.31 \pm 4.29$ & 0.905 \\
\hline Religion & & & 0.332 \\
\hline Buddhism & $7(10.9)$ & $3(10.3)$ & \\
\hline Catholic & $9(14.1)$ & $4(13.8)$ & \\
\hline Protestantism & $29(45.3)$ & $10(34.5)$ & \\
\hline No religion & $15(23.4)$ & $12(8.4)$ & \\
\hline Others & $4(6.3)$ & $0(0.0)$ & \\
\hline Unemployed & $40(62.5)$ & $14(48.3)$ & 0.218 \\
\hline Living alone & $19(29.7)$ & $2(7.4)$ & $0.002 \star \star$ \\
\hline Self-recognized diagnosis & & & $0.001 * *$ \\
\hline Depressive disorders & $18(28.1)$ & $4(13.7)$ & \\
\hline Bipolar spectrum disorders & $8(12.5)$ & $0(0.0)$ & \\
\hline Schizophrenia spectrum disorders & $29(45.3)$ & $0(0.0)$ & \\
\hline Medical illness & $9(14.1)$ & $7(24.1)$ & \\
\hline Under treatment for diagnosis & $46(71.9)$ & $4(13.7)$ & $0.001 * \star$ \\
\hline Smoker & $28(43.75)$ & $17(58.6)$ & 0.683 \\
\hline Reason for suicidal ideation & & & 0.201 \\
\hline School achievement & $0(0.0)$ & $3(10.3)$ & \\
\hline Future career & $6(9.3)$ & $2(6.9)$ & \\
\hline Social problem & $12(18.7)$ & $5(17.2)$ & \\
\hline Financial burden & $27(42.2)$ & $10(34.4)$ & \\
\hline Interpersonal problem & $9(14.0)$ & $11(37.9)$ & \\
\hline Others & $10(15.6)$ & $1(3.4)$ & \\
\hline Method of suicide & & & 0.298 \\
\hline Drug intoxication & $35(54.6)$ & $9(31.0)$ & \\
\hline Wrist cutting & $6(9.3)$ & $5(17.2)$ & \\
\hline Stabbing abdomen & $3(4.6)$ & $1(3.4)$ & \\
\hline Hanging & $9(14.0)$ & $4(13.7)$ & \\
\hline Drowning & $6(9.3)$ & $2(6.9)$ & \\
\hline Burning & $0(0.0)$ & $1(3.4)$ & \\
\hline Others & $5(7.8)$ & $7(24.1)$ & \\
\hline Familial suicide history & $13(20.3)$ & $11(37.9)$ & 0.053 \\
\hline Beck Depression Inventory & $48.98 \pm 13.84$ & $44.34 \pm 13.54$ & 0.909 \\
\hline Barratt Impulsiveness Scale & $27.09 \pm 8.41$ & $30.17 \pm 8.44$ & 0.855 \\
\hline Buss-Perry Aggression Questionnaire & $83.71 \pm 38.47$ & $89.00 \pm 34.17$ & 0.242 \\
\hline AUDIT-C & $2.85 \pm 3.62$ & $3.68 \pm 4.40$ & 0.062 \\
\hline Beck Hopelessness Scale & $9.67 \pm 5.45$ & $8.68 \pm 5.24$ & 0.980 \\
\hline Scale for Suicidal Ideation & $18.03 \pm 9.86$ & $14.00 \pm 10.02$ & 0.904 \\
\hline Brief Reason for Living Inventory & $44.01 \pm 16.22$ & $45.03 \pm 13.32$ & 0.221 \\
\hline Modified Childhood Trauma Questionnaire & $26.59 \pm 12.71$ & $27.68 \pm 12.04$ & 0.998 \\
\hline Social Support Scale & $29.67 \pm 7.53$ & $29.31 \pm 9.18$ & 0.585 \\
\hline Family Relationship Scale & $63.62 \pm 15.31$ & $66.89 \pm 17.49$ & 0.380 \\
\hline
\end{tabular}

Values are presented as number only, number (\%), or mean \pm standard deviation.

MHC, mental healthcare center; GHC, general healthcare center; AUDIT-C, Alcohol Use Disorders Identification Test-Concise. $\star p<0.05, * \star p<0.01, * \star \star p<0.001$. 
Further, drug intoxication was the most commonly reported method of suicide attempt in both the groups $(\mathrm{n}=35,54.6 \%$ vs. $\mathrm{n}=9,31.0 \%)$.

\section{Characteristics related to suicidal risk}

There was a marginally significant difference in the number of MHC $(n=13,20.3 \%)$ and GMC $(n=11,37.9 \%$, $\mathrm{p}=0.053$ ) registrants who had a familial suicide history. However, there were no statistically significant group differences in their scores on any of the scales used in this study, including the BDI. However, their BDI scores were higher than the cutoff score for severe depression (48.98 \pm 13.84 and $44.34 \pm 13.54)$.

\section{DISCUSSION}

In this study, the prevalence of lifetime suicidal ideation and attempts was $73.7 \%$ and $35.8 \%$ among MHC registrants and $42.3 \%$ and $9.7 \%$ among GHC registrants, respectively. Furthermore, psychiatric diagnosis acknowledged by registrants was, as expected, higher among the MHC registrants because MHC mainly register psychiatric patients. In contrast, only $2 \%$ of the GHC registrants recognized their diagnoses of depressive disorders, but their BDI scores were higher than the cutoff score for severe depression. Furthermore, the GHC registrants obtained higher AUDIT-C scores. Similar results emerged for the subsamples of participants who had a history of suicidal ideation and attempts, and the differences between MHC and GHC registrants tend to be disappeared as deepening suicide behaviors from ideation to attempt.

These results are surprising because the lifetime prevalence of suicidal ideation and attempts that emerged in this study is substantially higher than the figures that have been reported in past community studies. According to the results of the World Health Organization Community Surveys, which were conducted across 21 countries $(\mathrm{N}>100,000)$, the lifetime prevalence of suicidal ideation and attempts was $9 \%$ and $3 \%$, respectively [11]. Further, a Korean nationwide study, which was conducted in 2016, found that the lifetime prevalence of suicidal ideation and attempts was $15.4 \%$ and $2.4 \%$, respectively [3]. Although it is difficult to draw parallels to past findings, the rate of suicidal ideation among the GHC registrants (42.3\%) was approximately 2.8 times higher than the figure that was reported in a past Korean study (15.4\%), and the rate of suicidal attempts (9.7\%) was approximately 4.0 times higher than previously reported percentages $(2.4 \%)$. These findings were even more surprising because most GHC registrants are not regarded as psychiatric patients. However, compared to Korea's general population, GHC and MHC registrants have demographic differences due to a large number of unemployed, people living alone, and the high proportion of chronic disease patients. These differences are probably the main reason why the suicidal ideation and suicide attempts were higher in this study compared to the Korean nationwide study or WHO community survey. In addition, there was a phrase on the cover of the questionnaire $<$ Suicidal behavior prevalence survey $>$, requesting an honest answer, especially when taking this survey, which may have contributed to these results. This questionnaire format was intended to conduct research focusing more directly on suicidal behavior. As a result, these measurements would lead to having higher suicidal prevalence than other extensive studies. Between the GMC and MHC registrants, we should pay attention to the GMC registrants. Any professional had not considered psychiatric screening or counseling would be necessary to this population. As a result, the GHC registrants were unaware of their psychiatric status, despite their high BDI and AUDIT-C scores.

Considering high suicidal prevalence of this study and the classical information that more than $90 \%$ of suicide attempters have a psychiatric disorder [12], it would be possible to assume there might be a lot of psychiatric patients who had not been evaluated in GHC. A past study, which was conducted using a nationally representative sample of Koreans, also found that only $17.4 \%$ of those who reported depressive symptoms had consulted a mental health professional regarding their symptoms [13]. Furthermore, the higher score of AUDIT-C in GHC would reflect there had been many unexposed alcohol problems.

Given that GHCs focus on the management of metabolic syndrome and chronic medical problems, undiagnosed depressive symptoms may be accompanied by physical illnesses in their patients. In particular, depressive symptoms and chronic medical illnesses are prevalent among older adults in Korea, often co-occur, and increase healthcare utilization [14]. Chronic physical pain is also related to undiagnosed depression [15]. In contrast, among the GHC registrants, the most commonly 
reported reasons for suicide were financial burden and interpersonal relationships. Their socioeconomic status such as unemployed and living alone might contribute to high suicidal rate [16].

However, the rate of mental health service utilization among the general public in Korea has been found to be low. According to a Korean nationwide study [3], only $9.6 \%$ of the general public consulted a psychiatrist regarding their mental health problems over their entire lifetime. This figure is substantially lower than what has been observed in the United States. where the public has experienced $14.2 \%$ of psychiatric consulting experience over the past year. The 12-month mental health service utilization survey of people with mental illnesses found that only $22.2 \%$ of the psychiatric patients in Korea use mental health services during their lifetime. This percentage is lower than the figures that have been reported for other countries such as Belgium (39.5\%), New Zealand (38.9\%), Spain (35.5\%), Mexico (male: $27.2 \%$, female: $37.5 \%$ ), and Australia (34.9\%). Furthermore, the lifetime utilization of mental healthcare services among patients with alcohol problem in Korea is lower (12.1\%) than other psychiatric problems (22.2\%). The high AUDIT-C scores that were obtained by the GHC registrants indicate that Korean patients with alcohol problems are more likely to seek the services of GHCs rather than MHCs.

There were significant differences in scores on scales such as the AUDIT-C, Scale for Suicidal Ideation, Brief Reasons for Living Inventory, and Family Relationship Scale between the MHC and GHC registrants who had a history of suicidal ideation. When compared to the GHC registrants, the $\mathrm{MHC}$ registrants obtained higher scores on the Scale for Suicidal Ideation and lower scores on the Brief Reasons for Living Inventory and Family Relationship Scale. Since Suicidal ideation score related to suicidal ideation severity, and Brief Reason for Living Inventory and Family Relationship Scale related to protective factors of suicide $[4,16]$, it suggests that MHC registrants would have a more risk of suicidality than GHC. The greater suicidality and vulnerability that were observed among the MHC registrants is not surprising because the MHC has been registering those with psychiatric diagnoses and problems from the very beginning.

Suicide attempters have no significant difference between MHC and GHC on the scale. Their scores on all the scales that assessed the risk factors for suicide were evenly high, and their scores on the scales that assessed the factors that protect against suicide were evenly low. It might be that population who had more severe suicidal behaviors converged more homogeneous group.

Meanwhile, psychiatric status such as elevated BDI, Beck Hopelessness Scale in MHC also need an attention. Specifically, $35.8 \%$ of the MHC registrants had a history of suicide. Their BDI scores were indicative of severe depression, and their scores on the Beck Hopelessness Scale fell within the moderate range. This suggests that those who are at high risk for suicide are not treated adequately in MHCs. Furthermore, a prior history of suicide is the strongest predictor of repeated suicide attempts [17]. Therefore, further management efforts should be taken.

This study has several limitations. First, the data were collected using self-report measures, and medical records were not available. Self-reported scale is generally regarded as critical information that can complement more objective measures [18]. In this study, some participants may have provided inaccurate information about their psychiatric diagnosis. Second, lifetime suicidal behaviors and the symptoms of mental illnesses were assessed using retrospective reports, which may have been adversely influenced by recall biases. Third, defensive attitudes among the participants may have resulted in the underestimation of the prevalence of suicidal behaviors; however, a very high prevalence rate was observed in this study. Finally, factor analysis was reserved not to exhibit excessive results. The study design was focused on the checking of suicidal prevalence and multiple scales.

This study is the first to have examined the suicidal behaviors of the registrants of public community healthcare centers in Korea. Moreover, characteristic and current status related with suicidality were also evaluated specifically by applying multiple scales. This research provided evidence for which the role of the gatekeeper of suicide and the routine screening of psychiatric problems including depression and alcohol use should be provided not only in MHC but also in GHC. Indeed, the implementation of an integrative psychiatric health management system in both MHCs and GHCs may be necessary. Future studies should aim to reduce suicidal behaviors by increasing the rate of utilization of public community healthcare centers. 


\section{CONCLUSION}

There are high suicidal risk potential population in the public community healthcare center, not only in MHC, but also in GHC. However, their suicidality and psychiatric comorbidities have not been adequately assessed and managed, even in MHCs. Enhancing screening and effective delivery for psychiatric services to both MHC and GMC registrants should be considered to establish the policy for community health promotion. Simultaneously, public community healthcare centers should be positioned as gatekeepers of suicidal behaviors. Based on the present findings, a detailed method of execution should be developed.

\section{CONFLICTS OF INTEREST}

The authors have nothing to disclose.

\section{ACKNOWLEDGEMENTS}

This study was supported by a grant from the Korea Healthcare Technology R\&D Project, Ministry of Health and Welfare, Republic of Korea (HI10C2020). The Ministry of Health and Welfare had no role in the study design; in the collection, analysis, and interpretation of data, in the writing of the report, or the decision to submit the paper for publication.

\section{ORCID}

Kyuhong Lee
https://orcid.org/0000-0003-4048-8533
Hoo Rim Song
https://orcid.org/0000-0001-8927-0530
Su Young Lee
https://orcid.org/0000-0003-3125-3409
Tae-Youn Jun
https://orcid.org/0000-0001-9516-0768
Hae Kook Lee
https://orcid.org/0000-0002-3941-2980
Jong-Hyun Jeong
https://orcid.org/0000-0003-3570-7607
Sun-Jin Jo
https://orcid.org/0000-0002-8465-9632

\section{REFERENCES}

1. Statistics Korea. 2018 Annual report on the cause of death statistics [Internet]. Daejeon: Statistics Korea; 2019 Sep 24 [cited 2020 Feb 22]. Available from: http://kostat.go.kr/ portal/korea/kor_nw/1/6/2/index.board?bmode=read\&bSeq $=\& a S e q=377606 \&$ page $\mathrm{No}=1 \&$ row Num $=10 \&$ navCount $=10$ $\&$ currPg $=\&$ searchInfo $=\&$ sTarget $=$ title $\&$ sTxt $=$.

2. Chen WJ, Chen CC, Ho CK, Lee MB, Lin GG, Chou FH. Community-based case management for the prevention of suicide reattempts in Kaohsiung, Taiwan. Community Ment Health J 2012;48:786-91.

3. Ministry of Health and Welfare. 2016 The survey of mental disorders in Korea [Internet]. Sejong: Ministry of Health and Welfare; 2017 Apr 13 [updated 2017 Apr 26; cited 2020 Feb 20]. Available from: http://www.mohw.go.kr/ react/jb/sjb030301vw.jsp?PAR_MENU_ID=03\&MENU_ $\mathrm{ID}=032901 \&$ CONT_SEQ $=339138$.

4. Brown GK, Beck A, Conwell Y, Goldston D, Jobes D, Linehan $\mathrm{M}$, et al. A review of suicide assessment measures for intervention research with adults and older adults. Pennsylvania: University of Pennsylvania; 2000.

5. Barratt ES. Factor analysis of some psychometric measures of impulsiveness and anxiety. Psychol Rep 1965;16:547-54.

6. Brown GL, Goodwin FK. Cerebrospinal fluid correlates of suicide attempts and aggression. Ann N Y Acad Sci 1986; 487:175-88.

7. Bush K, Kivlahan DR, McDonell MB, Fihn SD, Bradley KA. The AUDIT alcohol consumption questions (AUDITC): an effective brief screening test for problem drinking. Ambulatory Care Quality Improvement Project (ACQUIP). Alcohol Use Disorders Identification Test. Arch Intern Med 1998;158:1789-95.

8. Virginia CS, Lina EP, Teresa LS. Child and adolescent trauma measures: a review. New York: Children and Families Institute for Research, Support and Training; Fordham University Graduate School of Social Service; 2003.

9. Sarason IG, Levine HM, Basham RB, Sarason BR. Assessing social support: the social support questionnaire. J Personal Soc Psychol 1983;44:127-39.

10. Yang OK. Study on development of the family relationship scale. Korean J Fam Soc Work 2001;8:119-47.

11. Nock MK, Borges G, Bromet EJ, Alonso J, Angermeyer M, Beautrais A, et al. Cross-national prevalence and risk factors for suicidal ideation, plans and attempts. Br J Psychiatry 2008;192:98-105.

12. Hirschfeld RM, Russell JM. Assessment and treatment of suicidal patients. N Engl J Med 1997;337:910-5.

13. Kim JL, Cho J, Park S, Park EC. Depression symptom and professional mental health service use. BMC Psychiatry 2015;15:261.

14. Kim H, Park SM, Jang SN, Kwon S. Depressive symptoms, chronic medical illness, and health care utilization: findings from the Korean Longitudinal Study of Ageing (KLoSA). 
Int Psychogeriatr 2011;23:1285-93.

15. Lee HJ, Choi EJ, Nahm FS, Yoon IY, Lee PB. Prevalence of unrecognized depression in patients with chronic pain without a history of psychiatric diseases. Korean J Pain 2018;31:116-24.

16. Schreiber J, Culpepper L. Suicidal ideation and behavior in adults [Internet]. Waltham: UpToDate; 2019 [updated 2020 Oct 21; cited 2020 Mar 20]. Available from: https://www. uptodate.com/contents/suicidal-ideation-and-behavior-inadults.

17. World Health Organization. Preventing suicide: a global imperative. Geneva: World Health Organization; 2014.

18. McGrady A, Lynch DJ, Nagel RW, Tamburrino M. Coherence between physician diagnosis and patient self reports of anxiety and depression in primary care. J Nerv Ment Dis 2010;198:420-4. 